1 Lavin JP, Stephens RJ, Miodovnik M, Barden TP. Vaginal delivery in patients with a prior cesarean section. Obstet Gynecol 1982;59:135-48.

Evrard JR Gold EM. Cesan section and maternal mortality in Rhode Island. Incidence and risk factors, 1965-1975. Obstet Gynecol 1977;50: Island.

3 Duff $\mathrm{P}$, Southmayd $\mathrm{K}$, Read JA. Outcome of trial of labor in patients with a single low transverse caesarean for dystocia. Obstet Gynecol 1988;71:

4 Whiteside DC, Mahan CS, Cook JC. Factors associated with successful vaginal delivery after cesarean section. $\mathcal{F}$ Reprod Med 1983;28:785-8.

5 Flamm BL, Goings JR. Vaginal birth after cesarean section: is suspected fetal macrosomia a contraindication? Obstet Gynecol 1989;74:694-7.
6 Phelan JP, Clark SL, Diaz F, Paul RH. Vaginal birth after cesarean. Amf Obstet Gynecol 1987;157:1510-5.

Gardner MJ, Gardner SB, Winter PD. Confidence Interval Analysis (CIA) microcomputer program manual. London: BMJ, 1989.

Statistical package for the social sciences $X$. User's guide, 2 nd ed. New York: McGraw-Hill, 1986.

9 Molloy BG, Sheil O, Duignan NM. Delivery after caesarean section: review of 2176 consecutive cases. BMF 1987;294:1645-7.

10 Meehan FP, Burke G. Trial of labour following prior section; a 5 year prospective study (1982-1987). Eur J Obstet Gynaecol 1988;31:109-17.

(Accepted 17 fuly 1991 )

\title{
Differential effects of enalapril and atenolol on proteinuria and renal haemodynamics in non-diabetic renal disease
}

\author{
Alfred J Apperloo, Dick de Zeeuw, Henk E Sluiter, Paul E de Jong
}

\begin{abstract}
Objective-To compare the antihypertensive, renal haemodynamic and antiproteinuric effect of enalapril and atenolol in patients with proteinuria of non-diabetic origin.
\end{abstract}

Design-Prospective, double blind, randomised 16 week study after a pretreatment period of at least three weeks.

Setting-Outpatient nephrology and hypertension unit.

Patients -27 patients with proteinuria $(>300 \mathrm{mg}$ protein/day) of non-diabetic origin, moderately impaired renal function (creatinine clearance $30-90 \mathrm{ml} / \mathrm{min}$ ), and a pretreatment diastolic blood pressure of $>80 \mathrm{~mm} \mathrm{Hg}$.

Interventions-Treatment with enalapril $(10 \mathrm{mg} /$ day, adjusted between 5 and $40 \mathrm{mg}$, if necessary) or atenolol ( $50 \mathrm{mg} /$ day, adjusted between 25 and $100 \mathrm{mg}$ if necessary) titrated against a target fall in diastolic blood pressure to $<95 \mathrm{~mm} \mathrm{Hg}$ or of $>10 \mathrm{~mm} \mathrm{Hg}$, or both.

Main outcome measures-Blood pressure, renal haemodynamics, and urinary protein excretion.

Results-No differences were detected between the two groups before treatment. The falls in systolic and diastolic blood pressures during treatment were not significantly different between both groups. Proteinuria fell slightly with atenolol but significantly more with enalapril (mean change - 0.38 (95\% confidence interval -0.78 to 0.03$) v-1.2(-1.70$ to $-0.69) \mathrm{g} /$ day respectively, $\mathrm{p}<0.02)$ as did filtration fraction (mean change $-1.8(-2.9$ to -0.7$) v-3.8$ $(-4.9$ to $-2 \cdot 8) \%$ respectively. Serum potassium concentration increased with enalapril (mean change 0.63 (SD 0.51) v 0.19 (0.47) $\mathrm{mmol} / \mathrm{l}, \mathrm{p}<0.05)$.

Conclusions-Enalapril lowers proteinuria more than atenolol in patients with non-diabetic renal disease despite a similar blood pressure lowering effect of both drugs, and its antiproteinuric effect seems to be associated with the characteristic renal haemodynamic effect of angiotensin converting enzyme inhibitors. 9713 EZ Groningen, The Netherlands

Alfred J Apperloo, MD registrar in medicine Dick de Zeeuw, MD, lecturer in nephrology

Henk E Sluiter, $\mathrm{MD}$, registrar in nephrology

Paul E de Jong, MD, head of nephrology unit

Correspondence to: Dr Apperloo.

BMF 1991;303:821-4 are indeed superior to other antihypertensive treatment regimens in this respect remains to be proved. One of the key questions is whether the alleged antiproteinuric (or protective) effect of angiotensin converting enzyme inhibitors is caused by the lowering of systemic blood pressure itself or whether it results from a specific action on renal function. The few studies that have addressed this question in diabetic $c^{4-6}$ and non-diabetic ${ }^{10-11}$ renal disease generally indicated that angiotensin converting enzyme inhibitors are more effective in lowering proteinuria compared with conventional antihypertensive drugs. However, these studies had an open design. More importantly, many studies failed to obtain a similar blood pressure response with the drugs compared. In fact, angiotensin converting enzyme inhibitors seemed to induce a greater fall in blood pressure than the control drugs, leaving open the option that systemic blood pressure effects and not renal effects are the main mechanism by which angiotensin converting enzyme inhibitors reduce proteinuria.

To avoid this possible bias we studied the antiproteinuric and renal haemodynamic effects of the angiotensin converting enzyme inhibitor enalapril compared with the $\beta_{1}$ selective blocker atenolol in a randomised double blind design in 27 patients with proteinuria and non-diabetic renal disease.

\section{Patients and methods}

From a group of patients currently under study in a long term trial of the effects of antihypertensive treatment on the progression of loss of renal function in non-diabetic renal disease we selected the patients with proteinuria of more than $300 \mathrm{mg}$ a day, measured on three consecutive visits in the pretreatment period $(n=27)$. Other entry criteria were a creatinine clearance of $30-90 \mathrm{ml} / \mathrm{min}$, a diastolic blood pressure $>80 \mathrm{~mm} \mathrm{Hg}$, and no contraindications for treatment with a $\beta$ blocker or an angiotensin converting enzyme inhibitor. The cause of the renal disease in these 27 patients (five women, 22 men; mean (SD) age 49 (13) years) was chronic glomerulonephritis (13 patients), chronic interstitial nephritis or pyelonephritis (seven), and nephrosclerosis (seven). The study was approved by the local medical ethics committee. Informed consent was obtained from each patient.

All patients adhered to a sodium restricted diet (50-80 $\mathrm{mmol}$ sodium/day). Protein intake was $0 \cdot 8-1.0 \mathrm{~g} / \mathrm{kg}$ body weight in the patients with a creatinine clearance of $60-90 \mathrm{ml} / \mathrm{min}$ and $0 \cdot 6-0 \cdot 8 \mathrm{~g} / \mathrm{kg}$ body weight in those with a creatinine clearance of $30-60 \mathrm{ml} / \mathrm{min}$. All antihypertensive drugs were withdrawn at least three weeks before active treatment started. In the pretreatment period the patients were 
seen every one to two weeks. Thereafter they were randomised to receive either enalapril $10 \mathrm{mg} /$ day or atenolol $50 \mathrm{mg} /$ day in a double blind fashion. Each patient was assigned an allocation number in chronological order with respect to the date of entry to the trial, which corresponded with the number on his or her treatment phial. The study treatment (enalapril or atenolol) had been randomly distributed beforehand among these numbers. The goal of treatment was to lower diastolic blood pressure to $<95 \mathrm{~mm} \mathrm{Hg}$ or by $>10 \mathrm{~mm} \mathrm{Hg}$, or both. Patients were seen every four weeks during the subsequent four month titration period. If the target blood pressure was not reached the dose of the antihypertensive drug could be increased stepwise to either $40 \mathrm{mg}$ enalapril or $100 \mathrm{mg}$ atenolol/ day. If hypotensive symptoms occurred the dose could be lowered to $5 \mathrm{mg}$ enalapril or $25 \mathrm{mg}$ atenolol/day. Blood pressure, body weight, and serum and urinary electrolyte, creatinine, urea, and protein concentrations were measured during all visits. Glomerular filtration rate and effective renal plasma flow were measured at the end of the pretreatment period and at the end of the titration period ( 16 weeks).

Blood pressure and heart rate were recorded with a non-invasive automatic device (Dinamap) after 10 minutes' rest with patients supine. The mean of five recordings was used. The values registered for diastolic blood pressure were those corresponding to Korotkoff phase V. Electrolyte, creatinine, urea, and serum albumin concentrations were measured by a standard autoanalyser (SMAC, Technicon). Urinary protein concentration was measured by pyrogallolmolybdatecomplex method. The mean value of estimations from three 24 hour urine collections during the pretreatment period was used as the baseline value. Glomerular filtration rate and effective renal plasma flow were measured as the clearance of constantly infused iothalamate labelled with iodine- 125 and hippuran labelled with iodine-131 respectively. ${ }^{13}$ Both variables were corrected for standard body surface area $\left(1.73 \mathrm{~m}^{2}\right)$. The coefficient of variation of this method was $2 \cdot 2 \%$ and $5 \cdot 0 \%$ respectively. Filtration fraction, being an approximation for the filtered part of the renal plasma flow, was given as the ratio of glomerular filtration rate to effective renal plasma flow.

Statistics-Results are presented as mean (SD)

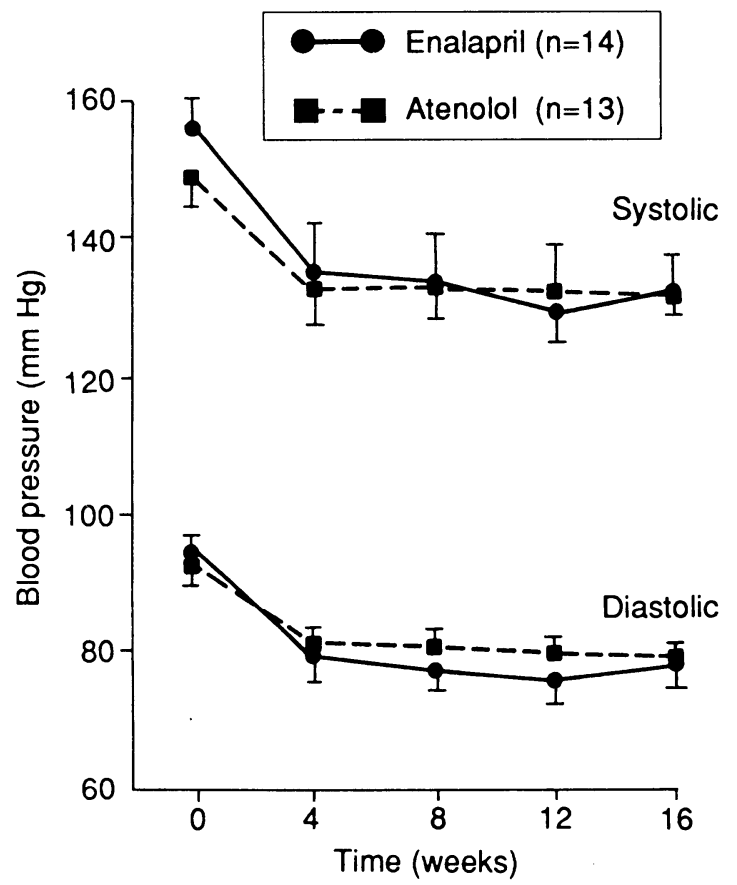

FIG 1-Mean (SE) systolic and diastolic blood pressures before and during 16 week course of enalapril or atenolol in patients with nondiabetic renal disease
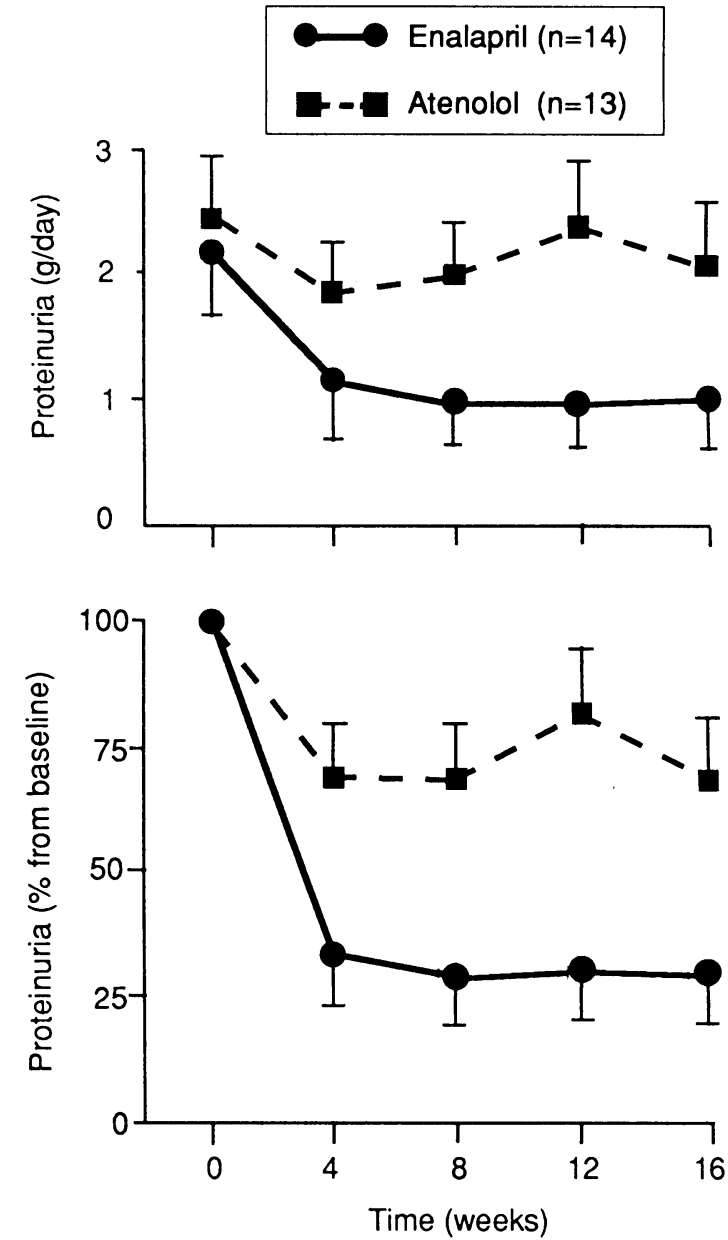

FIG 2-Twenty four hour urinary protein excretion before and during 16 week course of enalapril or atenolol in patients with non-diabetic renal disease. Top: mean (SE) proteinuria $\mathrm{g} / 24 \mathrm{~h}$; bottom: mean $(S E)$ individual value for proteinuria as percentage of pretreatment value

values and for main comparisons between treatments mean and $95 \%$ confidence intervals. Significance was taken as $\mathrm{p}<0 \cdot 05$. To check for successful randomisation the enalapril and atenolol populations were compared with respect to sex and diagnosis by means of the Fisher-Yates exact test and with respect to age and baseline values of proteinuria, glomerular filtration rate, systolic and diastolic blood pressures, and mean arterial pressure by means of Student's $t$ test. Treatment effects in both populations were tested by comparing the mean individual differences between data obtained at baseline and at week 16. Differences between the effects of the two treatment regimens were tested by comparing the mean of the individual changes in each group using Student's $t$ test. For each $t$ test there were 12 degrees of freedom for the enalapril group, 13 for the atenolol group, and 25 for the two drug group comparisons.

\section{Results}

Age, sex ratio, and histological diagnosis showed no differences in distribution in the enalapril $(n=13)$ and atenolol $(n=14)$ groups. No significant differences before treatment were present between the groups for any variable (table).

During treatment blood pressure fell from 157/94 $(13 / 10) \mathrm{mm} \mathrm{Hg}$ to $133 / 78(17 / 12) \mathrm{mm} \mathrm{Hg}$ with enalapril and from $149 / 92(18 / 10) \mathrm{mm} \mathrm{Hg}$ to $132 / 79(12 / 6)$ $\mathrm{mm} \mathrm{Hg}$ with atenolol $(\mathrm{p}<0.001$, for systolic and diastolic blood pressures with both treatments). The change in diastolic and systolic blood pressures from baseline values was not significantly different between both treatment groups (fig 1). Heart rate fell significantly in the atenolol group $(p<0.001)$ but not in the 
enalapril group. Body weight decreased in the enalapril group $(\mathrm{p}<0.02)$ but did not change in the atenolol group.

Urinary protein excretion fell significantly from $2 \cdot 2$ $(1.8)$ to $1.0(1.3) \mathrm{g} /$ day $(\mathrm{p}<0.001)$ in the enalapril group and not significantly, from $2 \cdot 4(1.9)$ to $2 \cdot 1(2 \cdot 0) \mathrm{g} /$ day in the atenolol group (fig 2, top). The change in proteinuria with atenolol was significantly different only at weeks $4(\mathrm{p}<0.01)$ and $8(\mathrm{p}<0.01)$. The decrease in proteinuria with atenolol became more clear when proteinuria was expressed as the percentage value, with the value before treatment taken as being $100 \%$ $(\mathrm{p}<0.02$ at weeks 4,8 , and 16) (fig 2, bottom). Whereas the changes in blood pressure were never significantly different between both treatment groups proteinuria plotted either as absolute values or percentage values decreased significantly more in the enalapril group from week 4 onwards $(\mathrm{p}<0.02, \mathrm{p}<0.05$ respectively). The decrease in proteinuria in the patients treated with enalapril was associated with clear renal haemodynamic changes (table): effective renal plasma flow increased significantly $(p<0.05)$; a significant, although numerically small, decrease in glomerular filtration rate occurred $(\mathrm{p}<0.005)$; and as a result the filtration fraction appreciably decreased $(p<0 \cdot 001)$. Interestingly, in the patients treated with atenolol the filtration fraction also decreased $(p<0.005)$. Its decrease was, however, significantly greater in the enalapril group $(p<0 \cdot 02)$. Serum potassium concentration increased during treatment with enalapril $(\mathrm{p}<0.001)$ but it did not during atenolol treatment. Serum urea concentration increased in the enalapril $(\mathrm{p}<0.001)$ and the atenolol $(\mathrm{p}<0.01)$ group. Sodium excretion was comparable in both groups during follow up and remained fairly stable during treatment (table). The values indicated that the patients actually consumed slightly more salt than advised (110-120 instead of $50-80 \mathrm{mmol} / \mathrm{day})$. Excretion of urea was also comparable in both groups, the value indicating a mean protein consumption of 55-75 g/day, corresponding to $0 \cdot 7-1 \cdot 1 \mathrm{~g} / \mathrm{kg}$ bodyweight, which is also slightly higher than the dietary advice, and increasing slightly in both groups during treatment $(p<0.01)$.

\section{Discussion}

This study shows that with a similar fall in blood pressure, urinary protein excretion decreases more with the angiotensin converting enzyme inhibitor enalapril than with the $\beta_{1}$ selective blocker atenolol in patients with non-diabetic renal disease. This suggests that the fall in urinary protein excretion during enalapril treatment is not due to lowering blood pressure itself but may be the consequence of the characteristic renal haemodynamic profile of this class of drugs.

To our knowledge this is the first double blind trial comparing the antiproteinuric effect of an angiotensin converting enzyme inhibitor with that of another antihypertensive drug in non-diabetic renal disease. Thus far, a greater antiproteinuric effect of angiotensin converting enzyme inhibitors has been suggested only by retrospective analysis ${ }^{10}$ or by open trials in diabetic ${ }^{45}$ and non-diabetic renal disease, ${ }^{10} 11$ comparing the angiotensin converting enzyme inhibitor with a $\beta$ blocker, ${ }^{4}$ a calcium entry blocker, ${ }^{56}$ triple treatment, ${ }^{10}$ or methyldopa." The conclusions from those studies

Effects of enalapril and atenolol on systemic and renal variables

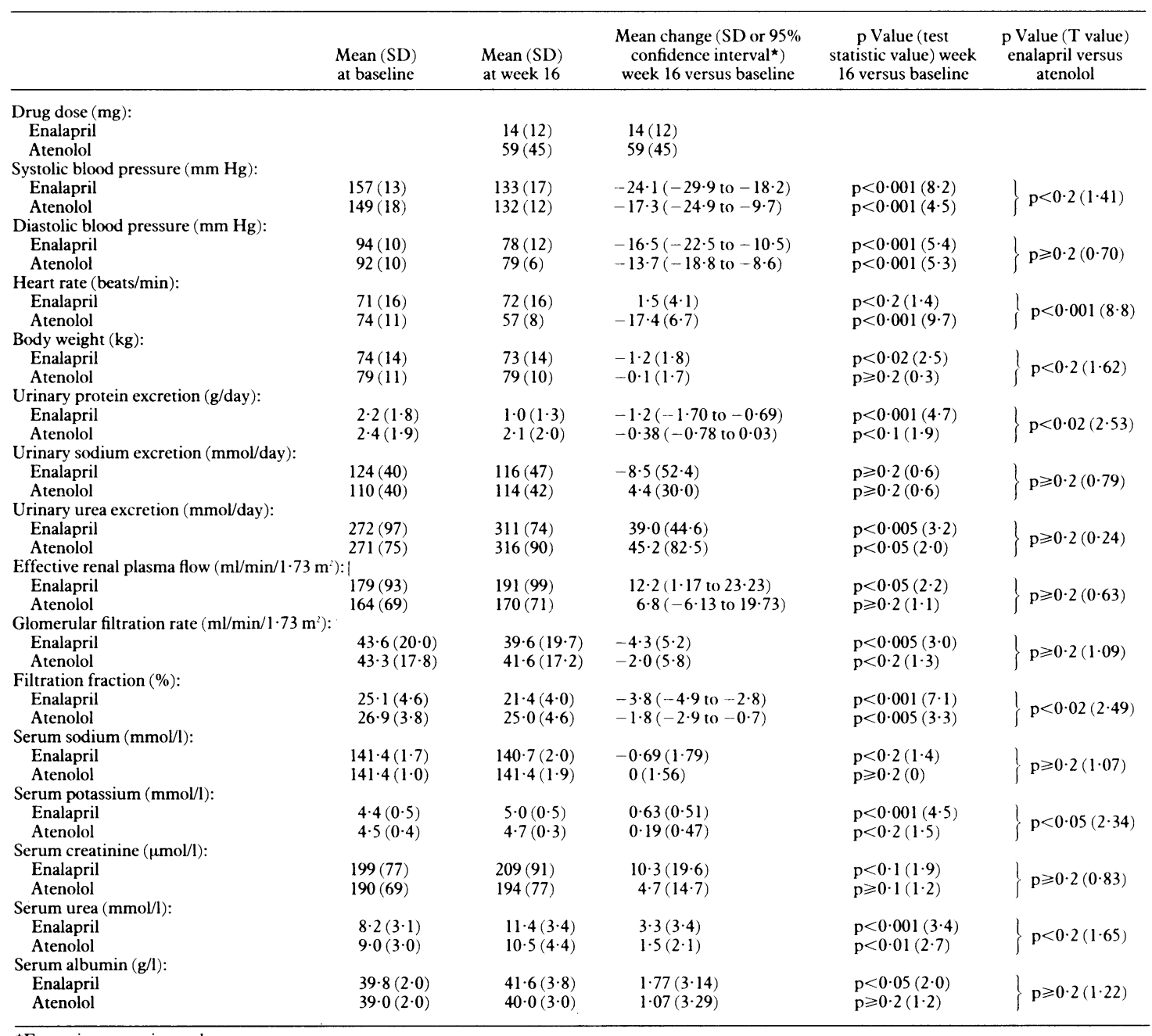


were commonly biased by the fact that blood pressure fell more in the group treated with the angiotensin converting enzyme inhibitor than in that treated with the other antihypertensive agent. ${ }^{4} 111$

Björck et al recently showed in diabetic patients that enalapril lowered proteinuria whereas metoprolol did not. ${ }^{4}$ Extrapolating these results in diabetic patients to patients with non-diabetic renal disease is, however, difficult. Owing to the afferent renal vasodilatation present in diabetic patients, ${ }^{14}$ changes in blood pressure could more easily result in changes in intraglomerular capillary pressure, and thus in urinary protein excretion, than in non-diabetic patients.

As enalapril lowers proteinuria more effectively than atenolol it may be argued that the antiproteinuric effect is related to the specific renal haemodynamic effects of the angiotensin converting enzyme inhibitor. Animal studies have shown that inhibition of the converting enzyme results in a lowering of intraglomerular capillary pressure. ${ }^{15}$ The fall in filtration fraction observed during angiotensin converting enzyme inhibition in humans can be used as an indirect measure for a fall in efferent arteriolar resistance and thus in intraglomerular capillary pressure. ${ }^{16}$ Indeed those above mentioned comparative studies that also included renal haemodynamic data showed that the filtration fraction fell during treatment with the angiotensin converting enzyme inhibitor but not during the other antihypertensive treatment. ${ }^{517}$ In that respect it is noteworthy that in this study atenolol, which is known to interfere in the renin-angiotensin system, did exert small but significant renal haemodynamic effects that showed a similar trend to those occurring with enalapril. During atenolol treatment the filtration fraction fell, although to a lesser extent than during enalapril treatment. This suggests that an antihypertensive drug may lower proteinuria only when it also lowers the filtration fraction.

Changes in dietary protein intake may also result in changes in proteinuria. ${ }^{18}$ Excretion of urea (which reflects dietary protein intake) did not decrease during the 16 week follow up and, moreover, never differed between the two groups. The difference in the antiproteinuric effect between both groups therefore cannot be due to differences in protein intake.

No clinical side effects were observed in our patients. Although pretreatment blood pressure was in the normotensive range in some of the patients, there were no complaints of hypotension with the doses used. Serum potassium concentration increased in the patients receiving enalapril; its increase could be managed adequately with dietary potassium restriction and did not prompt withdrawal of the angiotensin converting enzyme inhibitor.

The follow up was too short to permit any conclusion about the possible effects of these treatments in preventing progressive decline in renal function. The more pronounced fall in proteinuria and in filtration fraction during enalapril treatment may, however, suggest that enalapril could afford more renal protection in the long term. Firstly, the degree of proteinuria is a prognostic variable for progressive deterioration of renal function. ${ }^{19}$ Secondly, with filtration fraction as an indirect measure of intraglomerular capillary pressure a greater fall in this variable could also argue for a better prognosis for renal function.
We conclude that enalapril lowers urinary protein leakage more than atenolol in patients with nondiabetic renal disease. This suggests that the antiproteinuric effect during angiotensin converting enzyme inhibition is related more to the specific renal effects than to the antihypertensive effect itself.

We thank Mrs P T Hesling-Kuiper for secretarial help, Mrs A Drent-Bremer for technical help, Mrs G Sienot for laboratory help, and Mrs B J Beusekamp for dietary help. We thank Mr A Hovestad of Merck, Sharp, and Dohme, Haarlem, for his cooperation and for also kindly supplying the drugs, and Dr E Wattel, Department of Mathematics, Free University, Amsterdam, for blinded statistical analysis.

1 Taguma Y, Kitamoto Y, Futaki G, et al. Effect of captopril on heavy proteinuria in azotemic diabetes. $N$ Engl $\mathcal{G}$ Med 1984;313:1617-20.

2 Hommel E, Parving HH, Mathiessen E, et al. Effect of captopril on kidney function in insulin-dependent diabetic patients with nephropathy. $B M \mathcal{F}$ 1986;293:467-70

3 Marré $M$, Leblanc $H$, Suarez L, et al. Converting enzyme inhibition and kidney function in normotensive diabetic patients with persistent microalbuminuria. $B M f$ 1987;294:1448-52.

4 Björck S, Mulec H, Johnsen SA, Nyberg G, Aurell M. Contrasting effects of enalapril and metoprolol on proteinuria in diabetic nephropathy. BMF 1990;300:904-7.

5 Mimran A, Insua A, Ribstein J, et al. Contrasting effects of captopril and nifedipine in normotensive patients with incipient diabetic nephropathy. I Hypertens 1988;6:919-23.

6 Baba T, Murabayashi S, Takebe K. Comparison of the renal effects of the angiotensin converting enzyme inhibitor and calcium antagonist in hypertensive type 2 diabetic patients with microalbuminuria: a randomised controlled trial. Diabetologia 1989;32:40-4.

7 Herlitz H, Edeno C, Mulec H, Westberg G, Aurell M. Captopril treatment of hypertension and renal failure in systemic lupus erythematosus. Nephron 1984;38:253-6.

8 Reams GP, Bauer JH. Effect on enalapril in subjects with hypertension associated with moderate to severe renal dysfunction. Arch Intern Med 1986;146:2145-8.

9 Lagrue G, Robeva R, Laurent J. Antiproteinuric effect of captopril in primary glomerular disease. Nephron 1987;46:99-100.

10 Heeg JE, de Jong PE, van der Hem GK, de Zeeuw D. Reduction of proteinuria by angiotensin converting enzyme inhibition. Kidney Int 1987;32:78-83.

11 Heeg JE, de Jong PE, van der Hem GK, de Zeeuw D. Efficacy and variability of the antiproteinuric effect of ACE inhibition by lisinopril. Kidney Int 1989;36:272-9.

12 Bedogna V, Valvo E, Casagrande P, et al. Effects of ACE inhibition in normotensive patients with chronic glomerular disease and normal renal normotensive patients with chronic
function. Kidney Int 1990;38:101-7.

13 Donker AJM, van der Hem GK, Sluiter WJ, Beekhuis H. A radioisotope method for simultaneous determination of the glomerular filtration rate and the effective renal plasma flow. Neth $\mathcal{F}$ Med 1977;20:97-103.

14 Hostetter TH, Rennke HG, Brenner BM. The case for intrarenal hypertension in the initiation and progression of diabetic and other glomerulopathies. Am F Med 1982;72:375-80

15 Anderson S, Meyer TW, Rennke HG, Brenner BM. Control of glomerular hypertension limits glomerular injury in rats with reduced renal mass. f Clin Invest 1985;76:612-9.

16 Hall JE, Coleman TG, Guyton AC, et al. Control of glomerular filtration rate by circulating angiotensin II. Am f Physiol 1981;241:R190-7.

17 Heeg JE, de Zeeuw D, de Jong PE. The ACE inhibitor lisinopril reduces proteinuria in man by restoring glomerular permselectivity to proteins, without improving size selectivity for dextrans [abstract]. Kidney Int (in press).

18 Rosman JB, ter Wee PM, Piers-Becht TPM, et al. Prospective randomised trial of early dietary protein restriction in chronic renal failure. Lancet 1984;ii: $1291-6$

19 Williams PS, Fass G, Bone JM. Renal pathology and proteinuria determine progression in untreated mild/moderate chronic renal failure. $Q \mathcal{J}$ Med 1988;252:343-54.

(Accepted 17 fuly 1991)

\section{Correction}

\section{Review of neonatal screening programme for} phenylketonuria

An authors' error occurred in table I of this paper by Isabel Smith et al (10 August, $\mathrm{p}$ 333). The difference in number of infants tested for phenylketonuria and number of live births for Scotland for 1985 should read 622; the estimates of infants tested exceeded live births owing to inclusion of repeat tests. 